\section{The Second Russian Space Rocket}

A Russian multi-stage rocket was launched at about $9 \mathrm{hr}$. U.T. on September 12 and its final stage, weighing $1,511 \mathrm{kgm}$. (3,331 lb.) when empty of fuel, was projected towards the Moon with a speed of 7 miles per sec. At 18h. 40 m. U.T. on September 12, when it was about 90,000 miles from the Earth, the vehicle emitted a cloud of sodium vapour. This was observed from eastern Europe and Asia as a glow, which lasted about $5 \mathrm{~min}$. and was of stellar magnitude 5, in the constellation of Aquarius. At an unspecified point on its journey, the vehicle divided into two parts, an instrumented sphere weighing $390.2 \mathrm{kgm}$. (860 lb.) and the spent rocket. The sphere carried instruments to measure the magnetic fields of the Earth and Moon, the zones of radiation around the Earth, cosmic rays in space, the impacts of micrometeorites and the composition of interplanetary gas. It was stated that these experiments were successfully accomplished. The vehicle carried radio transmitters operating on some of, or all, the frequencies 19.993, 19.997, 20.003, 39.986 and $183.6 \mathrm{Mc} / \mathrm{s}$. The radio signals ceased abruptly at 21h. 02m. 24s. U.т. on September 13, when the instrumented sphere struck the surface of the Moon at long. $0^{\circ}$, lat. $30^{\circ} \mathrm{N}$., near the crater Archimedes.

While the vehicle was above the horizon in Britain, it was tracked by the Jodrell Bank radio telescope : the measurements made, of the direction, the Doppler frequency and the moment of impact, all confirmed that the vehicle followed very closely the trajectory given by the Russians. This second space rocket was similar to the first (launched on January 2, 1959; see Nature, 183, 83), which had a total weight of $3,245 \mathrm{lb}$., including $797 \mathrm{lb}$. of instruments in a spherical container, and performed similar experiments. The trajectories of the two rockets were also similar-both took about $35 \mathrm{hr}$. to reach the vicinity of the Moon--though the first rocket, instead of colliding with the Moon, flew past it to become the first artificial planet.

\section{Rocket Studies of Emissions caused by Solar Flares : National Science Foundation Grant}

Tre National Science Foundation has made a grant of 250,000 dollars to the U.S. Naval Research Laboratory for rocket observations of ultra-violet and X-ray emissions from solar flares. Principal investigator of the project is Dr. Herbert Friedman, superintendent of the Atmosphere and Astrophysics Division of the National Research Laboratory. The effect of the Sun's emissions upon the ionosphere and the resulting radio communication problems are of great theoretical and practical significance. Measurement and understanding of the origin of these emissions will be basic to an understanding of the solar flares themselves. Dr. Friedman will therefore launch a series of instrumented Nike-Asp rockets to make the necessary observations. The investigation will explore wave-lengths and altitudes at which only rudimentary observations have so far been made. Previous work by Dr. Friedman, Dr. Richard Tousey, and their co-workers at the National Research Laboratory has established the existence of intense radiations from the Sun in the wave-length regions under consideration. Dr. Friedman and his group at the Naval Research Laboratory were pioneers in the use of rockets for astronomical research, and astronomers credit his work with being among the most exciting and significant at present being carried on in the field. Instrumentation for the series of rocket observations will include Geiger counters to measure $\mathrm{X}$-rays in the 1-10 A. range, $X$-ray detectors for wave-lengths of 8-20 and 44-60 A., scintillation counters sensitive to hard X-rays in the $20-500 \mathrm{kV}$. range, and ion chambers sensitive to the helium emission lines at 584 and $314 \mathrm{~A}$.

\section{British Aid for Nato Scientific Courses}

Mr. H. Nicholls, Parliamentary Secretary to the Ministry of Works, stated in the House of Commons that the United Kingdom contribution to the fund established by the North Atlantic Council to promote international gatherings for the advanced study of special scientific topics would be about $£ 7,000$ in the first year and would be borne on the vote of the Department of Scientific and Industrial Research. This was a written answer on June 25 in response to a request for a statement regarding United Kingdom participation in the new North Atlantic Treaty Organization scheme for advanced study institutes. The funds would mostly be used for contributions to the teaching and administrative expenses of selected courses at institutes in a Nato country which offered intensive courses, usually at postdoctoral to professional level, in branches of the natural sciences and technology. Assistance might also be given to the travelling and scholastic expenses of participants from Nato countries.

\section{Graduates and National Service}

IN answering a question in the House of Commons on June 8, the Minister of Labour, Mr. Ian MacLeod, said that he was not prepared to extend the deferment arrangements for science and engineering graduates to men with other qualifications. This was the advice of his Technical Personnel Committee, which had considered last autumn difficulties said to be created for firms engaged in nuclear engineering and other industries by the call-up of non-graduates engaged on research. It was extremely difficult to distinguish between all the different professional qualifications that non-graduates have, but Mr. MacLeod said he would be willing to recejve a deputation of research directors to discuss a definition which might be as effective as the graduate definition, if Mr. Blenkinsop, his questioner, cared to organize such a deputation.

Research and Development Charges in Civil Nuclear Power

A question was asked in the House of Commons on June 15 regarding the proportion of research and development charges for the civil nuclear power programme borne by public funds through the Atomic Energy Authority. The Paymaster General, Mr. H. Maudling, in reply said that all research and development expenditure incurred by the Atomic Energy Authority was originally borne from public funds. However, it was intended that the expenditure attributable to the civil power programme should be recovered in due course in the form of royalties payable on the electricity stations and as part of the price charged for fuel elements. The Authority also recovered the cost of the consulting services from the electricity boards.

\section{Nuclear Reactor RB Accident in Yugoslavia}

Vouvme 9 of the Bulletin of the Boris Kidrich Institute of Nuclear Sciences contains twenty-five articles and two laboratory notes of technical interest contributed by members of the physies, physical 